\title{
Avaliação da resistência de genótipos de milho pipoca ao acúmulo de fumonisinas e à podridão de fusarium da espiga
}

\author{
Lorrant Cavanha Gabriel ${ }^{1,2}$, Carolina Bertuzzi Pereira ${ }^{1,2}$, Guilherme Passerini Bavia ${ }^{1,3}$, Marlon Coan ${ }^{1,4}$, Alan Augusto \\ Donel $^{1,5}$, Dauri José Tessmann ${ }^{1,6}$, Carlos Alberto Scapim ${ }^{1,6}$.
}

${ }^{1}$ Universidade Estadual de Maringá, Av. Colombo, 5790, 87020-900, Maringá-PR, Brasil; ${ }^{2}$ Engenheiros Agrônomos doutorandos do PGA/UEM, Universidade Estadual de Maringá, Av. Colombo, 5790, 87020-900, Maringá-PR, Brasil; ${ }^{3}$ Eng. Agrônomo Mestre pelo PGA/UEM, Universidade Estadual de Maringá, Av. Colombo, 5790, 87020-900, Maringá-PR, Brasil; ${ }^{4}$ Eng. Agrônomo, Doutor pelo PGA/UEM, Universidade Estadual de Maringá, Av. Colombo, 5790, 87020-900, Maringá-PR, Brasil; ${ }^{5}$ Eng. Agrônomo mestrando pelo PGA/UEM, Universidade Estadual de Maringá, Av. Colombo, 5790, 87020-900, Maringá-PR, Brasil; ' ${ }^{6}$ rofessores Drs. Associados da Universidade Estadual de Maringá, Av. Colombo, 5790, 87020-900, Maringá-PR, Brasil.

Autor para correspondência: Dauri José Tessmann (djtessmann@uem.br)

Data de chegada: 02/05/2017. Aceito para publicação em: 02/10/2017.

$10.1590 / 0100-5405 / 179360$

\section{RESUMO}

Gabriel, L.C.; Pereira, C.B.; Bavia, G.P.; Coan, M.; Donel, A.A.; Tessmann, D.J.; Scapim, C.A. Avaliação da resistência de genótipos de milho pipoca ao acúmulo de fumonisinas e à podridão de fusarium da espiga. Summa Phytopathologica, v.44, n.3, p.286-288, 2018.

A podridão de fusarium da espiga, causada pelo fungo Fusarium verticillioides, é uma das principais doenças do milho pipoca (Zea mays) no Brasil e, além da redução da produtividade, a ação do patógeno também resulta na contaminação dos grãos por micotoxinas do grupo das fumonisinas. O objetivo do estudo foi avaliar a resistência de genótipos de pipoca em relação a podridão de fusarium na espiga e ao acúmulo de fumonisinas nos grãos. O experimento foi conduzido em condições de campo com delineamento em blocos casualizados. A inoculação do patógeno da espiga foi artificial. Dentre os 22 genótipos avaliados, que incluíram 16 linhagens progenitoras e 6 variedades, verificaram-se diferenças significativas $(\mathrm{p}=0,05)$ em relação aos níveis de podridão de fusarium e à acumulação de fumonisinas B1, B2 e B3 nos grãos. A correlação de Spearman entre essas variáveis foi positiva, mas os coeficientes de correlação foram baixos $(\mathrm{r}=0,53 ; \mathrm{p}<0,0002)$, mostrando que para este grupo de genótipos a quantificação da podridão de fusarium na espiga tem pouco valor preditivo em relação ao teor de fumonisinas nos grãos. Acredita-se que estas informações são úteis para programas de melhoramento de milho pipoca no Brasil.

Palavras-chave: fusariose, Fusarium verticillioides, micotoxinas, Zea mays.

\section{ABSTRACT}

Gabriel, L.C.; Pereira, C.B.; Bavia, G.P.; Coan, M.; Donel, A.A.; Tessmann, D.J.; Scapim, C.A. Evaluation of resistance of popcorn maize genotypes to fumonisin accumulation and fusarium ear rot. Summa Phytopathologica, v.44, n.3, p.286-288, 2018.

Fusarium ear rot, caused by the fungus Fusarium verticillioides, is one of the major diseases of popcorn maize (Zea mays) in Brazil and, besides reducing productivity, the action of the pathogen results in the contamination of grains by mycotoxins of the fumonisin group. The aim of this study was to evaluate the resistance of popcorn genotypes to fusarium ear rot and to the accumulation of fumonisins in the grains. The experiment was conducted in the field by adopting a randomized block design. Pathogen inoculation in the ear was artificial. Among the 22 evaluated genotypes, which included
16 progenitor lines and 6 varieties, there were significant differences ( $p$ $=0.05$ ) in relation to the levels of fusarium rot and the accumulation of fumonisins B1, B2 and B3 in the grains. Spearman's correlation for these variables was positive, but the correlation coefficients were low $(r=0.53$; $\mathrm{p}<0.0002$ ), showing that for this group of genotypes the quantification of fusarium ear rot has a small predictive value in relation to fumonisin content in the grains. This piece of information is believed to be useful for breeding programs of popcorn maize in Brazil.

Keywords: fusariosis, Fusarium verticillioides, mycotoxins, Zea mays.

A baixa disponibilidade de cultivares de milho pipoca (Zea mays) com adaptação às diferentes condições agroclimáticas é um dos fatores que limitam a expansão da cultura no país (2). Outro problema importante são os danos de doenças fúngicas, como a podridão de fusarium da espiga, causada pelo fungo Fusarium verticillioides (Sacc.) Nirenberg. Essa doença é particularmente importante, porque além de causar a redução na produtividade das lavouras, também prejudica a qualidade dos grãos colhidos, causando redução no peso e tamanho, manchas, mofos e contaminação por fumonisinas. As fumonisinas são um grupo de micotoxinas produzidas primariamente por $F$. verticillioides durante o processo de colonização do milho, dentre as quais as mais importantes são a FB1 e a FB2, cujos teores máximos nos alimentos encontram-se regulamentados (1). A preocupação com a contaminação dos alimentos por fumonisinas decorre dos danos que estas substâncias causam à saúde humana e animal $(5,9)$.

O objetivo do trabalho foi avaliar um grupo de genótipos de milho pipoca, alguns deles utilizados como linhagens progenitoras em programas de melhoramento genético, em relação à resistência ao acúmulo de fumonisinas nos grãos e à podridão de fusarium na espiga. Um objetivo adicional foi correlacionar as duas variáveis, visando avaliar o potencial preditivo da resistência à doença em relação à contaminação por fumonisinas. Os resultados do estudo são importantes para programas de melhoramento genético de milho pipoca que visam, concomitantemente, o desenvolvimento de genótipos mais resistentes ao acúmulo de fumonisinas e à podridão de fusarium na espiga, os quais são ainda raros no Brasil.

O experimento foi conduzido na Fazenda Experimental Iguatemi $\left(23^{\circ} 25^{\prime} \mathrm{S} ; 51^{\circ} 57^{\prime} \mathrm{O}\right)$, pertencente à Universidade Estadual de Maringá, 
no município de Maringá, Paraná, durante a safra 2014/15. Foram semeados 22 genótipos de milho pipoca em delineamento experimental em blocos casualizados, com duas repetições. As parcelas experimentais constituíram-se de linhas de 6 metros de comprimento, com um espaçamento de 90 centímetros, e 25 a 30 plantas na linha. Em cada linha, 10 plantas foram inoculadas com $F$. verticillioides. O inóculo foi constituído por microconídios de três isolados do patógeno, cuja espécie foi previamente identificada pela técnica de reação da polimerase em cadeia, empregando oligonucleotídeos primers específicos para F. verticillioides (6). Para a produção de esporos, os isolados foram cultivados em placas de Petri de $90 \mathrm{~mm}$ de diâmetro contendo meio SNA (Spezieller Nährstoffarmer Ágar), a $28^{\circ} \mathrm{C}$ e fotoperíodo de 12 horas (4). A coleta dos esporos foi realizada após 15 dias de cultivo. A concentração final da suspensão de esporos foi de $4.10^{6}$ microconídios por $\mathrm{mL}$.

As espigas foram inoculadas pela injeção de suspensão de esporos na porção mediana da espiga $(2 \mathrm{~mL})$ e na ponta da espiga $(1 \mathrm{~mL})$, entre 12 a 16 dias após o lançamento do estigma, compreendendo a fase de grão leitoso do milho. Após a colheita, a avaliação de severidade foi realizada com base na porcentagem dos grãos manchados, necrosados ou mofados em cada uma das espigas de cada tratamento. Posteriormente, todos os grãos de cada espiga foram triturados e 20 gramas de cada amostra foram preparadas para a extração das fumonisinas com o solvente orgânico metanol. Prosseguiu-se então para o teste de ELISA direto com o kit de detecção de fumonisinas AgraQuant Fumonisin (0,25-5 ppm) Test Kit (Romer Labs Singapore Pte. Ltd.) e posterior leitura em espectrofotômetro a 450 nanômetros. Esse kit permite a quantificação das fumonisinas B1, B2 e B3.

As análises dos pressupostos básicos para a análise de variância foram realizadas. Os dados foram então transformados por logaritmo neperiano e submetidos ao teste de agrupamento de médias de ScottKnott, a 5\% de probabilidade, pelo Programa $\mathrm{R}$ através do pacote 'ExpDes.pt'. Também foi realizada entre as variáveis uma correlação de Spearman, pelo programa SAS (10).

A análise mostrou que houve diferenças entre os tratamentos para ambas as variáveis, acúmulo de fumonisinas $(\mathrm{p}<0,002)$ e severidade da doença $(\mathrm{p}<0,0005)$. O teste de Scott-Knott, a 5\% de probabilidade, permitiu o agrupamento dos genótipos de milho pipoca em dois grupos estatísticos, tanto em relação ao acúmulo de fumonisinas como à severidade da doença (Tabela 1).

A quantidade de fumonisinas acumulada nos grãos dos genótipos incluídos no estudo variou de 8,2 a 234,8 ppm, o que é considerada elevada. Na literatura, são poucos os estudos disponíveis em relação à resistência ao acúmulo de fumonisinas em milho pipoca. $\mathrm{O}$ estudo de Presello et al. (8), com apenas quatro genótipos e inoculação artificial, também verificou diferenças entre genótipos, porém esses acumularam menores teores de fumonisinas nos grãos (2,2 a 20,4 ppm) do que no estudo aqui apresentado. Com milho comum, o estudo de Kleinschmidt et al. (3) que envolveu 68 genótipos também mostrou diferenças significativas entre os genótipos e mostrou que com a inoculação artificial do patógeno a concentração de fumonisinas nos grãos variou de 4 a 255 ppm. Já com inoculação natural esses valores foram bem menores, de 0,7 a 14,6 ppm.

Existem três fatores que podem ter contribuído para o acúmulo de fumonisinas em níveis elevados no presente estudo. Primeiramente, a inoculação artificial que, tal como verificado por Kleinschmidt et al. (3), fez com que os genótipos apresentassem maior quantidade de fumonisinas do que quando comparado com materiais inoculados naturalmente no campo. Segundo, a ocorrência de elevada umidade
Tabela 1. Fumonisinas em grãos de milho pipoca e severidade da podridão de fusarium (T: dados transformados pela transformação 'ln'; DT: dados destransformados).

\begin{tabular}{|c|c|c|c|c|}
\hline \multirow{2}{*}{ Genótipos de milho pipoca } & \multicolumn{2}{|c|}{ Fumonisinas } & \multicolumn{2}{|c|}{ Severidade } \\
\hline & $\mathbf{T}$ & DT (ppm) & $\mathbf{T}$ & DT $(\%)$ \\
\hline Viçosa-L77 & $2,10 \mathrm{a}$ & 8,2 & $0,33 \mathrm{a}$ & 1,38 \\
\hline Beijaflor-L59 & $2,88 \mathrm{a}$ & 17,8 & $2,30 \mathrm{~b}$ & 9,90 \\
\hline P8-1-5-5 & $3,16 \mathrm{a}$ & 23,64 & $1,32 \mathrm{a}$ & 3,73 \\
\hline Beijaflor-L54 & $3,25 \mathrm{a}$ & 25,84 & $0,78 \mathrm{a}$ & 2,18 \\
\hline Ângela-L66 & $3,36 \mathrm{a}$ & 28,75 & $1,50 \mathrm{a}$ & 4,46 \\
\hline P9-1 & $3,62 \mathrm{a}$ & 37,52 & $2,74 \mathrm{~b}$ & 15,35 \\
\hline P9-1-2 & $3,72 \mathrm{a}$ & 41,18 & $1,04 \mathrm{a}$ & 2,82 \\
\hline P1-19 & $3,78 \mathrm{a}$ & 44,01 & $1,01 \mathrm{a}$ & 2,73 \\
\hline P6-11 & $3,95 \mathrm{a}$ & 51,97 & $0,48 \mathrm{a}$ & 1,61 \\
\hline P-18 & $3,98 \mathrm{a}$ & 53,57 & $1,65 \mathrm{a}$ & 5,18 \\
\hline P7-4-11 & $4,01 \mathrm{a}$ & 55,1 & $1,61 \mathrm{a}$ & 4,98 \\
\hline Viçosa-L88 & $4,43 \mathrm{~b}$ & 83,9 & $1,68 \mathrm{a}$ & 5,34 \\
\hline $\mathrm{P} 20$ & $4,50 \mathrm{~b}$ & 89,99 & $1,29 \mathrm{a}$ & 3,61 \\
\hline Viçosa-L75 & $4,57 \mathrm{~b}$ & 96,88 & $1,60 \mathrm{a}$ & 4,92 \\
\hline P7-2-4 & $4,62 \mathrm{~b}$ & 101,13 & $2,10 \mathrm{~b}$ & 8,11 \\
\hline P19 & $4,64 \mathrm{~b}$ & 103,59 & $3,07 \mathrm{~b}$ & 21,34 \\
\hline P8-2 & $4,65 \mathrm{~b}$ & 105,11 & $3,22 \mathrm{~b}$ & 24,78 \\
\hline P9-4-5 & $4,71 \mathrm{~b}$ & 110,54 & $2,27 \mathrm{~b}$ & 9,61 \\
\hline P1-17 & $4,88 \mathrm{~b}$ & 132,24 & $2,51 \mathrm{~b}$ & 12,21 \\
\hline P9-1-3 & $4,90 \mathrm{~b}$ & 134,51 & $0,60 \mathrm{a}$ & 1,81 \\
\hline P7-2-3 & $5,14 \mathrm{~b}$ & 171,48 & $1,44 \mathrm{a}$ & 4,20 \\
\hline P8-1-5-13 & $5,46 \mathrm{~b}$ & 234,85 & $2,36 \mathrm{~b}$ & 10,51 \\
\hline
\end{tabular}

*Médias seguidas de letras distintas nas colunas diferem entre si pelo teste de Scott-Knott a 5\% de probabilidade. A avaliação de severidade foi realizada com base na porcentagem dos grãos manchados, necrosados ou mofados em cada uma das espigas de cada tratamento. CV Fumonisinas $=14,8 \%, \mathrm{CV}$ Severidade $=35,19 \%$

e temperaturas durante todo o período do experimento certamente contribuiu para o desenvolvimento da doença e o acúmulo de fumonisinas (7). Por último, o cultivo de sucessão milho sobre milho há mais de dez anos na área do ensaio permitiu um grande acúmulo de inóculo de $F$. verticillioides, aumentando a severidade de infecção das espigas e o acúmulo de fumonisinas.

A correlação de Spearman entre as variáveis foi positiva, porém o coeficiente de correlação foi baixo $(\mathrm{r}=0,5352 ; \mathrm{p}<0,002)$ (Figura 1), evidenciando assim, que a quantificação da severidade da podridão da espiga apresenta baixo valor preditivo para o teor de fumonisinas nos grãos. Com base na literatura, os índices de correlação entre severidade de podridão e fusarium e teor de fumonisina nos grãos apresentam muitas divergências, o que sugere uma grande variação na base genética dos genótipos de milho considerados para cada estudo, a qual sofre também importante influência do ambiente (7).

O estudo permitiu a verificação das diferenças entre genótipos de milho pipoca em relação ao acúmulo de fumonisinas e resistência à podridão de fusarium na espiga e a baixa correlação entre essas variáveis. As linhagens progenitoras que foram analisadas constituem uma base genética importante de milho pipoca no Brasil, pelo qual espera-se que essas informações sejam úteis para os programas de melhoramento genético de milho pipoca do país. 


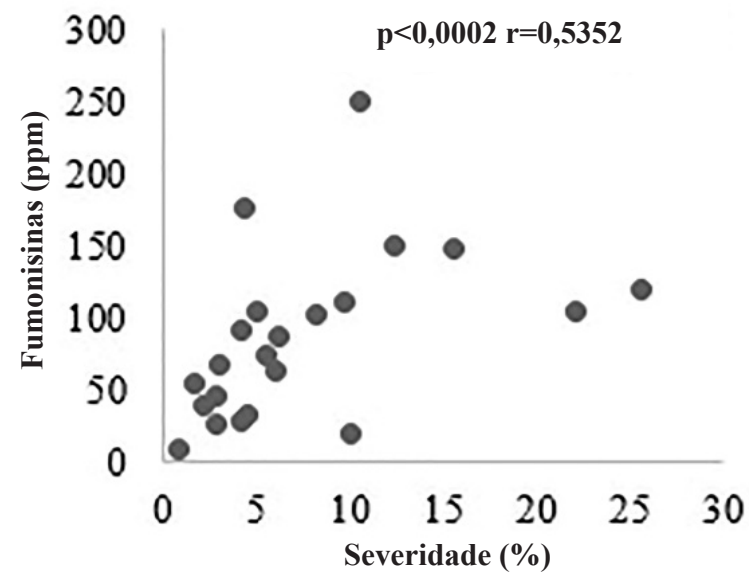

Figura 1. Correlação de Spearman entre acúmulo de fumonisinas e severidade da podridão de fusarium da espiga em genótipos de milho pipoca.

\section{AGRADECIMENTOS}

Ao apoio financeiro recebido do Programa Pronex CNPq-Fundação Araucária e a todos que contribuíram para o trabalho.

\section{REFERÊNCIA}

1. Agência Nacional de Vigilância Sanitária - ANVISA. Resolução da Diretoria Colegiada - RDC No 138, de 8 de fevereiro de 2017. Disponível em: http://portal.anvisa.gov.br/documents/10181/3219534/RDC 1382017. pdf/b36e60b0-5112-43dc-9142-932f502fc46b?version. Acesso em: 15 de abril de 2017.

2. Filho, I.A.P.; Cruz, J.C.; Pacheco, C.A.P.; Costa, R.V. Agência Embrapa de Informação Tecnológica. Milho pipoca. Disponível em: http://www.agencia. cnptia.embrapa.br/gestor/milho/arvore/CONT000fy9zxynl02wx5ok0pvo4k359f3bo9.html, 2017. Acesso em 14 abril 2017.

3. Kleinschmidt, C.E.; Clements, M.J.; Maragos, C.M.; Pataky, J.K.; White, D.G. Evaluation of food-grade dent corn hybrids for severity of Fusarium ear rot and fumonisin accumulation in grain. Plant Disease, Saint Paul, v.89, n.3, p.291-297, 2005.

4. Leslie, J.F.; Summerell, B.A. The Fusarium Laboratory Manual. Ames, Iowa: Blackwell Professional, 2006. 388p.

5. Marasas, W.F.O. Discovery and occurrence of the fumonisins. A historical perspective. Environmental Health Perspectives, Durham, v.109, n.2, p.239-243, 2001.

6. Mulè, G.; Susca, A.; Stea, G.; Moretti, A. A species-specific PCR assay based on the calmodulin partial gene for identification of Fusarium verticillioides, F. proliferatum and F. subglutinans. European Journal of Plant Pathology, Dordrecht, v.110, n.5, p.495-502, 2004.

7. Munkvold, G.P.; Desjardins, A.E. Fumonisins in maize: can we reduce their occurrence? Plant Disease, Saint Paul, v.81, n.6, p.556-565, 1997.

8. Presello, D.A.; Iglesias, J.; Botta, G.; Eyhérabide, G.H. Severity of Fusarium ear rot and concentration of fumonisin in grain of Argentinian maize hybrids. Crop Protection, Surrey, v.26, p.852-855, 2007.

9. Requena, F.; Saume, E.; Leon, A. Micotoxinas: Riesgos y prevención. Revista Zootecnia Tropical, Maracay, v.23, n.4, p.393-410, 2005.

10. SAS Institute Inc. SAS ${ }^{\circledR} 9.3$ System Options: Reference, Second Edition. Cary, SAS Institute Inc., 2011. 